\title{
Multiple-unit tablet of probiotic bacteria for improved storage stability, acid tolerability, and in vivo intestinal protective effect
}

This article was published in the following Dove Press journal:

Drug Design, Development and Therapy

7 April 2016

Number of times this article has been viewed

\author{
Hee Jun Park' \\ Ga Hyeon Lee' \\ Joonho Jun' \\ Miwon Son' \\ Myung Joo Kang ${ }^{2}$ \\ 'Dong-A Pharmaceutical Co. Ltd., \\ Yongin, Gyeonggi, ${ }^{2}$ College of \\ Pharmacy, Dankook University, \\ Cheonan, Chungnam, Korea
}

Correspondence: Myung Joo Kang College of Pharmacy, Dankook University, I 9 Dandae-ro, Dongnam-gu, Cheonan 330-714, Chungnam, Korea

Tel +824 I 550 I 446

Fax +82 4I 5507899

Email kangmj@dankook.ac.kr

\begin{abstract}
The aim of this study was to formulate probiotics-loaded pellets in a tablet form to improve storage stability, acid tolerability, and in vivo intestinal protective effect. Bacterialoaded pellets primarily prepared with hydroxypropyl methylcellulose acetate succinate were compressed into tablets with highly compressible excipients and optimized for flow properties, hardness, and disintegration time. The optimized probiotic tablet consisted of enteric-coated pellets $(335 \mathrm{mg}$ ), microcrystalline cellulose (Avicel PH102, $37.5 \mathrm{mg}$ ), and porous calcium silicate $(25 \mathrm{mg})$ and allowed whole survival of living bacteria during the compaction process with sufficient tablet hardness (13 kp) and disintegration time (14 minutes). The multiple-unit tablet showed remarkably higher storage stability under ambient conditions $\left(25^{\circ} \mathrm{C} / 60 \%\right.$ relative humidity) over 6 months and resistance to acidic medium compared to uncoated strains or pellets. Repeated intake of this multiple-unit tablet significantly lowered plasma level of endotoxin, a pathogenic material, compared to repeated intake of bare probiotics or marketed products in rats. These results, therefore, suggest that the multiple-unit tablet is advantageous to better bacterial viability and gain the beneficial effects on the gut flora, including the improvement of intestinal barrier function.
\end{abstract}

Keywords: probiotics, multiple-unit tablet, bacterial viability, acid resistance, intestinal barrier function

\section{Introduction}

Recently, there has been a surge in clinical evidence regarding the therapeutic benefits of probiotic bacteria including Lactobacillus, Bifidobacteria, and Enterococcus species to gut health and a growing commercial interest in food and/or pharmaceutical application of these bacteria. ${ }^{1}$ One beneficial effect of probiotics on human gut flora is the restoration of impaired intestinal barrier function. ${ }^{2,3}$ Regular intake of probiotic strains stimulates the growth of preferred microorganisms, crowds out potentially detrimental strains, and reinforces the natural defense mechanisms. ${ }^{4,5}$ However, formulation of probiotic bacteria along with other ingredients, or even alone, in a stable dosage form is hampered by their extremely poor viability during the preparation process and/or the storage period. Majority of microorganisms generally exhibit extreme liability to oxygen, temperatures, low $\mathrm{pH}$, and additives.${ }^{6,7}$ Moreover, the viability of living bacteria in gastric fluid is rather poor. Few of them exhibit resistance to adverse environmental conditions to colonize the mucosal membrane of small and/or large intestine., ${ }^{8,9}$

Enteric coating techniques have been explored in order to protect living bacteria from the unfavorable interaction within the dosage form, adverse gastrointestinal environments ( $\mathrm{pH}$, enzymes, bile salts, etc), and to deliver bacteria to the human intestine. ${ }^{10}$ 
We previously reported that enteric-coated pellets (ECPs) prepared with hydroxypropyl methylcellulose acetate succinate (HPMCAS) offered profound colonization of living bacteria in the intestine. ${ }^{11}$ However, from a pharmaceutical aspect, compression of ECPs into a single-tablet dosage form is preferred to provide accurate dosage, ease of administration, and better patient acceptance. Moreover, probiotic tablets with suitable excipients and compression force ensured higher bacterial stability in gastric juice compared to powder dosage form. ${ }^{12}$ In spite of these advantages of tabletized pellets, compacting coated pellets into tablets is quite challenging because polymer-coated pellets may be ruptured and/or fused into a nondisintegrating matrix during compression, ${ }^{13}$ diminishing the protection for living bacteria. Moreover, the compression process could reduce the viability of freeze-dried living bacteria. ${ }^{14,15}$

Several approaches have been attempted to avoid pellet rupture during the compression procedure and to guarantee appropriate physical properties of multiparticulate tablet. These approaches include modulation of coated film plasticity and compression with highly compressible excipients. ${ }^{13}$ Cushioning agents including microcrystalline cellulose (MCC) granules, crospovidone, lactose, porous inorganic materials, and wax beads protect the coated film integrity during the compaction process, with plastic and/or elastic deformation or brittle properties. ${ }^{13,16,17}$ To find the finest composition, case-specific formulation study is essential because the aforementioned techniques are largely dependent on the shape and size of pellets and the flexibility of coated polymers. ${ }^{17}$ To the best of our knowledge, investigation on compression of bacteria-loaded pellets into tablet dosage form has not been reported yet.

The objectives of the current study were: 1) to build a stable single-tablet dosage form of probiotics encapsulated in ECPs and 2) to evaluate the intestinal protective effect of living bacteria on the inhibition of intestinal penetration of pathogenic materials in vivo. Lactobacillus acidophilus- and Enterococcus faecalis-loaded ECPs were prepared through dry powder coating process. Subsequently, probiotic-loaded beads were mixed with pharmaceutical cushioning agents and directly compressed into tablets named ECPs embedded tablet (ECPs-T). Several cushioning agents such as MCC, lactose monohydrate, corn starch, and porous calcium silicate were exploited and assessed in terms of granular flow properties, tablet hardness, and disintegration time. Survival rate of living bacteria in the preparation process, under the storage condition, and in acidic medium of optimized probiotic tablet was compared to uncoated bacteria, ECPs, and marketed products. In addition, the intestinal protective effect of the multiple-unit tablet from pathogenic materials was assessed in rats by determining its inhibitory effect on intestinal penetration of orally administered endotoxin, a potent inflammatory stimulant after crossing the intestinal mucosa.

\section{Materials and methods Materials}

Lyophilized L. acidophilus $\left(8.2 \times 10^{9} \mathrm{CFU} / \mathrm{g}\right)$ and E. faecalis $\left(15.5 \times 10^{9} \mathrm{CFU} / \mathrm{g}\right)$ were obtained from Cell Biotech Co. Ltd, (Gimpo, Korea) and Ildong Pharmaceutical Co., Ltd. (Cheongju, Korea), respectively. HPMCAS (Aqoat ${ }^{\mathbb{B}}$ AS-LF) and low-substituted hydroxypropyl cellulose (L-HPC LH-11) were kindly provided by Shin-Etsu Chemicals Ltd. (Tokyo, Japan). Several grades of MCC granules (Avicel PH101, 102, 105, and 200) were purchased from FMC Biopolymer (Philadelphia, PA, USA). Corn starch, lactose monohydrate, calcium silicate, and magnesium stearate were obtained from Whawon Pharm. Co., Ltd (Seoul, Korea). Crospovidone (Kollidon-CL) was kindly provided by BASF Chemicals Co. Ltd. (Florham, NJ, USA). All other chemicals were of reagent grade and used without further purification.

\section{Preparation of probiotics-loaded tablet dosage form}

The ECPs loaded single-tablet dosage form was prepared using a two-step process: preparation of probiotics-loaded pellets using dry powder coating technique and direct compression of ECPs with active compounds and pharmaceutical excipients after dry mixing using a high-speed mixer. The compositions of ECPs-Ts are shown in Table 1. ECP-loaded pellets were fabricated with the dry powder coating technique as previously reported, ${ }^{11,18}$ with slight modification. Briefly, an appropriate amount of lyophilized bacteria, sodium alginate, calcium carbonate, and plasticizers (glyceryl monooleate, triethyl citrate, and acetylated monoglyceride) were mixed in a high-speed mixer (Model Diosna P 1/6; DIOSNA Dierks \& Söhne GmbH, Osnabrück, Germany). Subsequently, powder form of HPMCAS was supplied to the slurry and further mixed for 3 minutes at $300 \mathrm{rpm}$ using the main blade. Bacteria-loaded primary seeds were cured with additionally supplied HPMCAS powder and plasticizers to form coating layer on the surface of seeds more densely. Talc was then introduced as lubricant, and the pellets were cured at $40^{\circ} \mathrm{C}$ for 30 minutes. Afterward, the probioticsloaded pellets were admixed with other active compounds (natural gastroprotective compounds and digestive enzymes) 
Table I Composition of the probiotics-loaded ECPs-T formulation

\begin{tabular}{|c|c|c|c|c|c|c|c|c|c|}
\hline Excipients & $\mathbf{F I}$ & F2 & $\mathbf{F 3}$ & F4 & $\mathbf{F 5}$ & F6 & F7 & $\mathbf{F 8}$ & F9 \\
\hline ECPs & 335 & 335 & 335 & 335 & 335 & 335 & 335 & 335 & 335 \\
\hline L-HPC II & 22.5 & 22.5 & 22.5 & 22.5 & 22.5 & 22.5 & 22.5 & 22.5 & 22.5 \\
\hline Crospovidone & 5 & 5 & 5 & 5 & 5 & 5 & 5 & 5 & 5 \\
\hline HPC-EXF & 20 & 20 & 20 & 20 & 20 & 20 & 20 & 20 & 20 \\
\hline Avicel PHI02 & 37.5 & - & - & - & - & - & 37.5 & 37.5 & 37.5 \\
\hline Lactose monohydrate & - & 37.5 & - & - & - & - & - & - & - \\
\hline Corn starch & - & - & 37.5 & - & - & - & - & - & - \\
\hline Avicel PHI05 & - & - & - & 37.5 & - & - & - & - & - \\
\hline Avicel PHIOI & - & - & - & - & 37.5 & - & - & - & - \\
\hline Avicel PH200 & - & - & - & - & - & 37.5 & - & - & - \\
\hline Calcium silicate & - & - & - & - & - & - & 15 & 25 & 35 \\
\hline Magnesium stearate & 15 & 15 & 15 & 15 & 15 & 15 & 15 & 15 & 15 \\
\hline
\end{tabular}

Note: Unit of measurement is mg; “-” indicates not added or not included in the formula.

Abbreviations: ECPs-T, enteric-coated pellets embedded tablet; ECPs, enteric-coated pellets; F, formulation; HPC, hydroxypropylcellulose; L-HPC, low-substituted hydroxypropyl cellulose.

and pharmaceutical ingredients using a drum mixer (Namjoo Co., Hwaseong, Korea) at $20 \mathrm{rpm}$ for 5 minutes. The mixture was blended manually with magnesium sulfate and subsequently compressed directly into tablets using a rotary tableting machine (Riva Piccola, Hampshire, UK) equipped with a punch $(15.4 \times 8.4 \mathrm{~mm})$ under a pressure force of $14 \pm 1 \mathrm{kN}$.

\section{Physical characterization of ECPs-T}

Before the compaction process, the flow property of each mixture of ECPs and pharmaceutical excipients was assessed in terms of angle of repose $\left(^{\circ}\right)$ and Carr's compression index (CI; \%). The angle of repose of each granule was measured using a powder flow tester (GTB; Erweka GmbH, Heusenstamm, Germany). Briefly, $\sim 5 \mathrm{~g}$ of sample was passed through a funnel located $4 \mathrm{~cm}$ above the bench surface to form a gravimetric cone. The angle of formed cone was determined optically by a laser. The height of stainless steel funnel was $10 \mathrm{~mm}$. The orifice size was $10 \mathrm{~mm}$. CI value of each sample was calculated after determining bulk and tapped densities of powder using a tap density tester (SVM 102; Erweka $\mathrm{GmbH}$ ). Approximately $10 \mathrm{~g}$ of sample was filled into the test tube. The initial bulk volume was determined after manually tapping the cylinder. The tapped volume was then measured following 1,250 taps with $250 \mathrm{drops} / \mathrm{min}$. CI value of each composition was calculated using the following equation: ([ $\left.\left.P_{\text {tap }}-P_{\text {bulk }}\right] / P_{\text {tap }}\right)$, where $P_{\text {tap }}$ is the tap density and $P_{\text {bulk }}$ is the bulk density.

The compressed ECPs-T tablets were tested for crushing strength using a hardness tester (TBH 310MD; Erweka $\mathrm{GmbH})$. Disintegration time of ECPs-T was evaluated using a disintegration tester according to the US pharmacopoeia monograph (Erweka GmbH). Briefly, each tablet was placed in the basket rack assembly and covered by transparent plastic disk. The tablet was immersed in $800 \mathrm{~mL}$ of distilled water maintained at $37^{\circ} \mathrm{C}$. A time required for tablets to disintegrate completely without leaving any solid residue was visually evaluated.

\section{Morphological characterization of ECPs-T}

Morphological features of the probiotics-loaded pellet and the cross-sectional appearance of ECPs-T were observed using scanning electron microscope (SEM, SNE-3000M; SEC Co. Ltd., Suwon, Korea). The ECPs and cross-sectioned ECPs-T were placed onto a copper grid using double-sided tape. The sample was coated with gold using an automatic magnetron sputter coater system (MCM-100; SEC Co. Ltd.). The morphology of each sample was observed under an SEM operated at an acceleration voltage of $30.0 \mathrm{kV}$.

\section{Bacterial viability during the preparation process, storage, and acidic medium Viability of living bacteria during the preparation process}

Immediately after fabrication, probiotic-loaded ECP or ECPs-T formulations containing $20 \mathrm{mg}$ viable bacteria was suspended in sterilized phosphate-buffered saline (PBS, Biowhittaker ${ }^{\circledR}$; Lonza, Walkersville, MD, USA). ECPs-T tablet was powdered gently with a spatula and mortar. The suspension was then vigorously vortexed for 10 minutes to liberate living bacteria into the medium. The medium was serially diluted in PBS at a concentration of 30-300 CFU/mL. Each diluent (1 mL) was transferred to $10 \mathrm{~mL}$ de Man, Rogosa and Sharpe (MRS) agar medium or Streptococcus faecalis agar medium (MB Cell, Los Angeles, CA, USA) to culture L. acidophilus and E. faecalis, respectively. After 5 minutes of solidification of the agar media, plates were placed in aerobic or anaerobic jars, 
respectively. The resulting number of colonies on the plates was counted after incubation of 72 hours. Relative survival (\%) of each strain was determined by dividing the initial cell count by the CFU/g of samples and multiplying by 100 .

\section{Viability of living bacteria under storage conditions}

Each formulation such as lyophilized bare probiotics, uncoated probiotic tablet, ECPs, ECPs-T, and marketed products were transferred into light-resistant high-density polyethylene bottle and stored in stability test chambers (VP2000; Vötsch Industrietechnik $\mathrm{GmbH}$, Balingen, Germany) under ambient conditions $\left(25^{\circ} \mathrm{C} / 60 \%\right.$ relative humidity). At 1 and 6 months poststorage, bacterial viability of each sample was determined according to the protocol described earlier.

\section{Acid resistance of probiotics}

Each formulation containing $10^{7}-10^{8}$ of L. acidophilus or E. faecalis strains was incubated in $30 \mathrm{~mL}$ of $0.1 \mathrm{M}$ hydrochloride solution ( $\mathrm{pH}$ 1.2) with a stirring speed of $200 \mathrm{rpm}$ in a shaking incubator and maintained at $37^{\circ} \mathrm{C}$. Following 30 minutes of incubation, residual ECPs-T was suspended in PBS solution ( $\mathrm{pH}$ 6.8) for 10 minutes to release the living bacteria from the solid dosage form. ${ }^{19}$ Relative survival (\%) of each strain (L. acidophilus and E. faecalis) was determined by dividing the $\mathrm{CFU} / \mathrm{g}$ at 30 minutes by the initial cell count on day 0 followed by multiplying by 100 .

\section{Effect of ECPs-T on intestinal penetration of endotoxin in rats}

\section{Animals}

Sprague Dawley rats (Central Lab. Animal Inc., Seoul, Korea) weighing 300-350 g were used in this study to evaluate the intestinal membrane-strengthening effect of ECPs-T. Animals were kept under standard laboratory conditions with free access to a standard diet and water ad libitum. The animal study was performed in accordance with the US National Institutes of Health (NIH) guideline "Principles of Laboratory Animal Care" (NIH publication No 85-23, revised 1996). The study protocol was approved by the Institutional Animal Care and Use Committee of Dong-A ST, Co., Ltd., Research Center in Yongin, Korea.

\section{Treatments}

Rats were assigned to six groups ( $n=5$ per group) by a stratified randomization scheme designed to achieve similar mean body weights. All samples were suspended in 3\% hydroxypropyl methylcellulose solution and administered orally through a syringe fitted with a flexible oral zonde needle. Sham group received only 3\% hydroxypropyl methylcellulose solution. Negative control group received vehicle solution containing no probiotic ECPs-T. Four test groups received bare bacteria, ECPs-T, commercialized product VSL\#3 (Danisco, Madison, WI, USA), or TGK-IR (Kowa Shinyaku Co., Ltd., Tokyo, Japan) at the same dose $\left(5 \times 10^{8} \mathrm{CFU}\right)$ for 7 days. After 12 hours of fasting, the negative control and the four treatment groups received an oral dose of endotoxin at $60 \mathrm{mg} / \mathrm{kg}$, while the sham group received sterilized PBS solution. Blood samples were drawn from the jugular vein at 3 hours posttreatment. They were collected into heparinized tubes. Endotoxin level in the plasma was measured using Limulus Amebocyte Lysate Test Cartridges and Endosafe PTS Portable Test System (Charles River Laboratories) following the manufacturer's instructions.

\section{Statistical analysis}

Statistical analysis was performed using Student's $t$-test. Statistical significance was considered when $P$-value was $<0.05$ unless otherwise indicated.

\section{Results and discussion Formulation and physical characteristics of ECPs-T}

To the best of our knowledge, this study represents the first exploration to construct a multiple-unit tablet dosage form of probiotic bacteria to improve intestinal protective effect. We assumed that tabletization of bacteria-loaded pellets with compatible pharmaceutical excipients could further enhance the storage stability and the acid tolerance of microorganisms by providing an additional physical barrier to protect them from environmental stress more effectively. In the matrix compartment, several active substances such as natural gastroprotective compounds $(5 \mathrm{mg}$ of swertia herbal powder, $5 \mathrm{mg}$ of cinnamon bark powder, and $25 \mathrm{mg}$ of methylmethionine sulfonium chloride), digestive enzymes (15 mg of enteric-coated pancreatin granule), and acid-stable Bacillus subtilis (30 mg for each tablet) were included (data not shown) because they are beneficial for treating diarrhea and balancing intestinal flora along with living strains. Two kinds of hydroxypropylcellulose (HPCs) (L-HPC 11 and HPC-EXF, $45 \mathrm{mg}$ ) and crospovidone ( $5 \mathrm{mg}$ ) were used as binders and disintegrating agent, respectively.

Compressible excipients such as MCC (Avicel PH102), corn starch, and lactose monohydrate were compressed with ECPs to avoid pellet rupture during the compression procedure and to assure appropriate physical properties of 
A

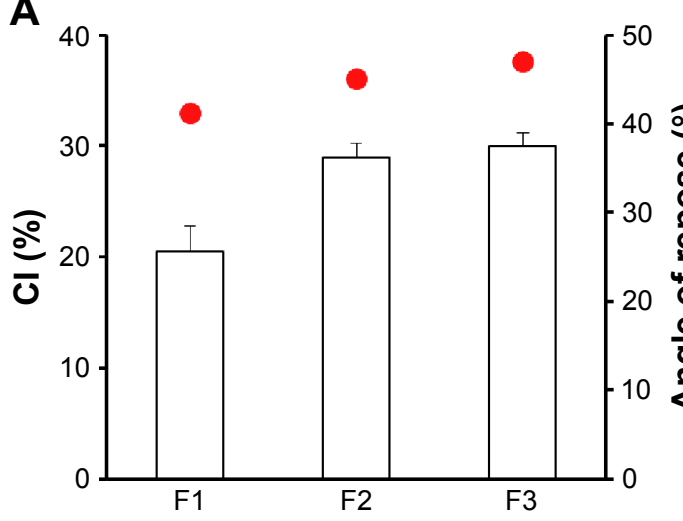

B

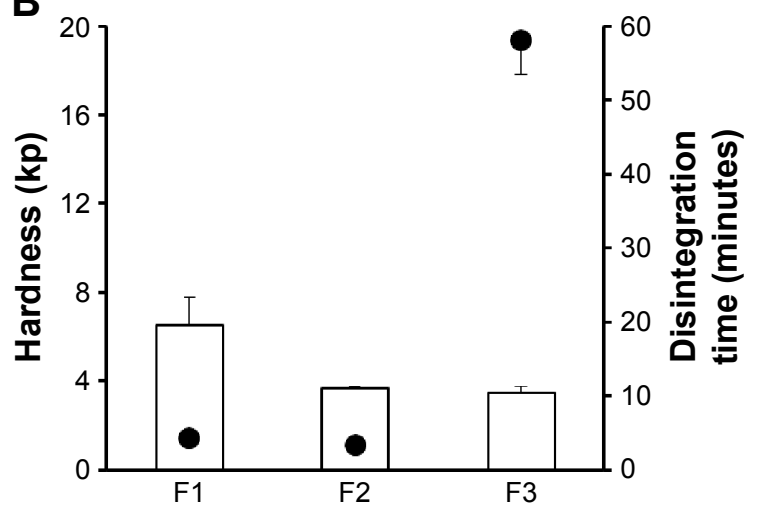

Figure I Effect of cushioning agents on (A) flow properties of ECP powders; $\mathrm{Cl}$ and angle of repose (indicated by the red circles), and (B) tablet hardness and disintegration time (indicated by the black circles) in distilled water.

Note: Data are expressed as mean \pm SD values $(n=3)$.

Abbreviations: $\mathrm{Cl}$, compressibility index; $\mathrm{ECP}$, enteric-coated pellet; $\mathrm{SD}$, standard deviation; F, formulation.

the multiple-unit tablet of probiotic bacteria. As shown in Figure 1A, the employment of Avicel PH102 (F1) remarkably improved the flow properties of ECTs compared to lactose monohydrate (F2) or corn starch (F3), providing low compressibility index and angle of repose values of $\sim 20 \%$ and $40^{\circ}$, respectively. Moreover, F1 showed faster disintegration time of $<5$ minutes due to the low coefficient of friction of MCC granules. ${ }^{20,21}$ In addition, excellent plastic deformability and dry binding ability of $\mathrm{MCC}^{22}$ dominantly attributed to superior mechanical strength $(6.5 \mathrm{kp})$ to the $\mathrm{F} 1$ compared to the $\mathrm{F} 2$ and F3 formulas (Figure 1B). In consistent with our results, AlIbraheemia et $\mathrm{al}^{23}$ reported that $\mathrm{MCC}$ provided better physical properties over sodium starch glycolate (elastic deformation material) or lactose (brittle material) during the compaction process of coated particles. Therefore, MCC was chosen for further preparation of ECPs-T formulae.
In order to investigate the effect of particle size on physical properties of ECPs-T system, different grades of MCC granules (F1, F4-F6) were employed. All grades of MCC granules are sphere shaped and behave as plastic materials ${ }^{24}$ with different particle sizes; the mean diameters of Avicel PH105, PH101, PH102, and PH200 were 20, 50, 100, and $180 \mu \mathrm{m}$, respectively. As the particle size became larger, the flow ability of the probiotic ECPs was improved, gradually lowering CI value from $30 \%$ to $20 \%$ (Figure $2 \mathrm{~A}$ ). Similarly, the angle of repose was also decreased when the mean particle diameter was increased. Smaller particles tended to build a more dense structure by increasing cohesion and/or adhesion forces, preventing particles from free flowing. On the other hand, larger granules triggered the disintegration of tablets, although the mechanical strength of probiotic tablets was comparable (Figure 2B) regardless of granular size.
A

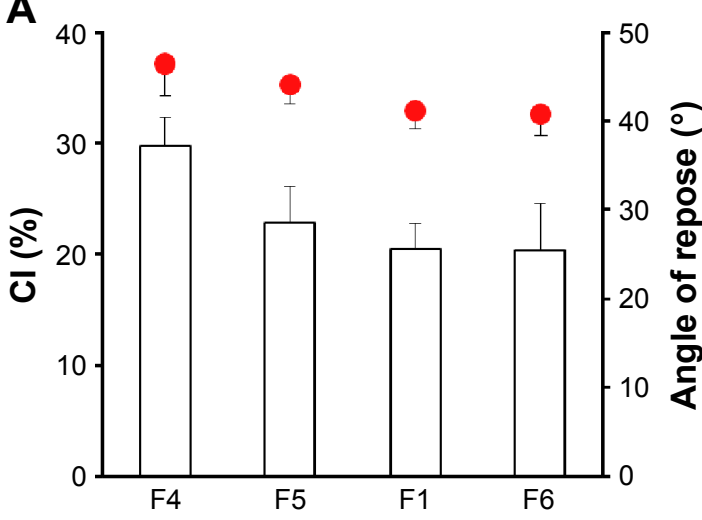

B

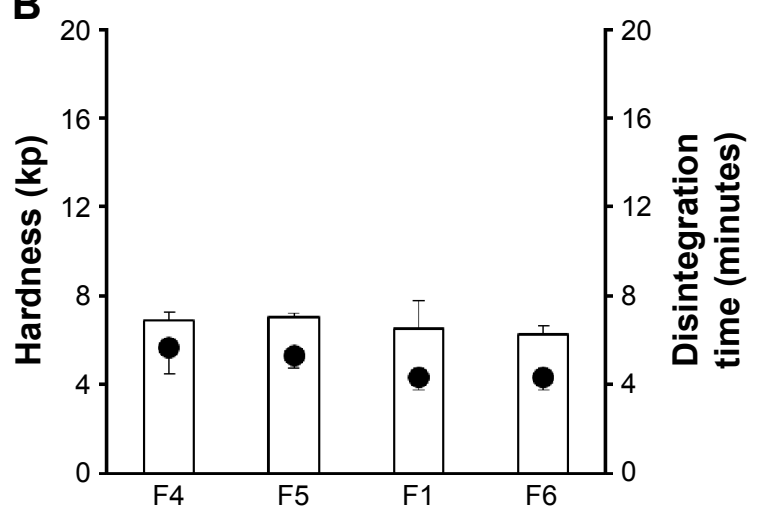

Figure 2 Effect of particle sizes of MCC granules on (A) flow properties of ECP powders; $\mathrm{Cl}$ and angle of repose (indicated by the red circles), and (B) tablet hardness and disintegration time (indicated by the black circles) in distilled water.

Note: Data are expressed as mean $\pm S D$ values $(n=3)$.

Abbreviations: $\mathrm{Cl}$, compressibility index; ECP, enteric-coated pellet; MCC, microcrystalline cellulose; SD, standard deviation; F, formulation. 

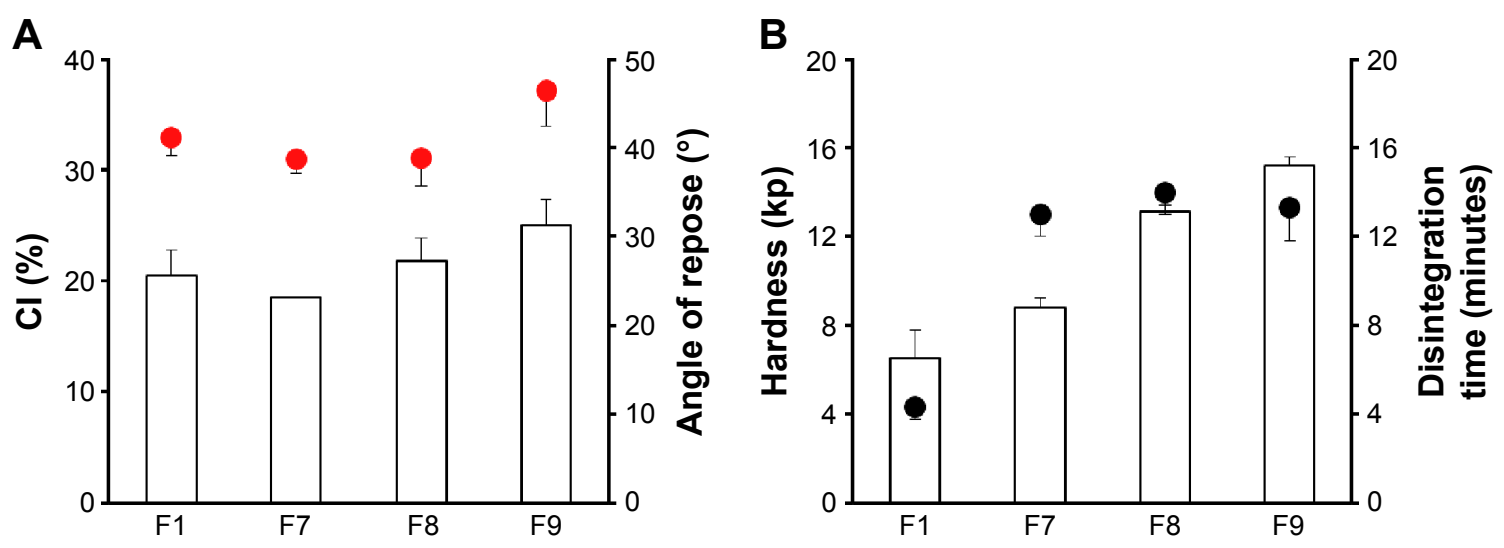

Figure 3 Effect of calcium silicate combined with MCC on (A) flow properties of ECP powders; $\mathrm{Cl}$ and angle of repose (indicated by the red circles), and (B) tablet hardness and disintegration time (indicated by the black circles) in distilled water.

Note: Data are expressed as mean \pm SD values $(n=3)$.

Abbreviations: $\mathrm{Cl}$, compressibility index; $\mathrm{ECP}$, enteric-coated pellet; MCC, microcrystalline cellulose; SD, standard deviation; F, formulation.

There was no significant difference in physical properties between F1 and F6. Therefore, Avicel PH102 was adopted as a primary cushioning agent to formulate ECPs-T.

In order to further strengthen the probiotic tablet, different amounts of porous calcium silicate was employed with Avicel PH102 (F7-F9). The addition of calcium silicate did not remarkably affect on the flow properties of ECP powders (Figure 3A). On the other hand, as shown in Figure 3B, increasing the amount of calcium silicate yielded higher mechanical strength. The hardness of F1, F7, F8, and F9 was $5.2,9.2,13.1$, and $15.6 \mathrm{kp}$, respectively. Porous calcium silicate has high plasticity and low elastic recovery during the compression process due to its highly porous structure. ${ }^{25}$ These properties predominantly contributed to the suitable compressibility and hardness of ECPs-T. Moreover, it can be predicted that smaller organic material would be embedded between larger granules and/or adsorbed onto the surface of ECPs and/or MCC, which can lead to more dense and durable structure of ECPs-T. A previous study revealed that calcium silicate-based matrix had high mechanical strength through substantial plastic deformation and brittle fracture of the porous particles under the compression force. ${ }^{26}$ On the other hand, the addition of inorganic particles quite delayed the disintegration time of tablets (Figure 3B). The increased compactness and water-insoluble property of inorganic material perhaps prevented rapid water penetration into the matrix, retarding the disintegration time of ECPs-T. Nevertheless, F8 and F9 were within our required disintegration time and hardness ( $<20$ minutes and $>10 \mathrm{kp}$, respectively). Hence, F8 formula containing $37.5 \mathrm{mg}$ MCC Avicel PH102 and $25 \mathrm{mg}$ calcium silicate was used as the optimized ECPs-T.

\section{Morphological observation of ECPs-T}

Morphological features of ECPs and cross-sectional appearance of ECPs-T F8 were scrutinized under SEM. As shown in Figure 4A, the pellets obtained via dry powder coating
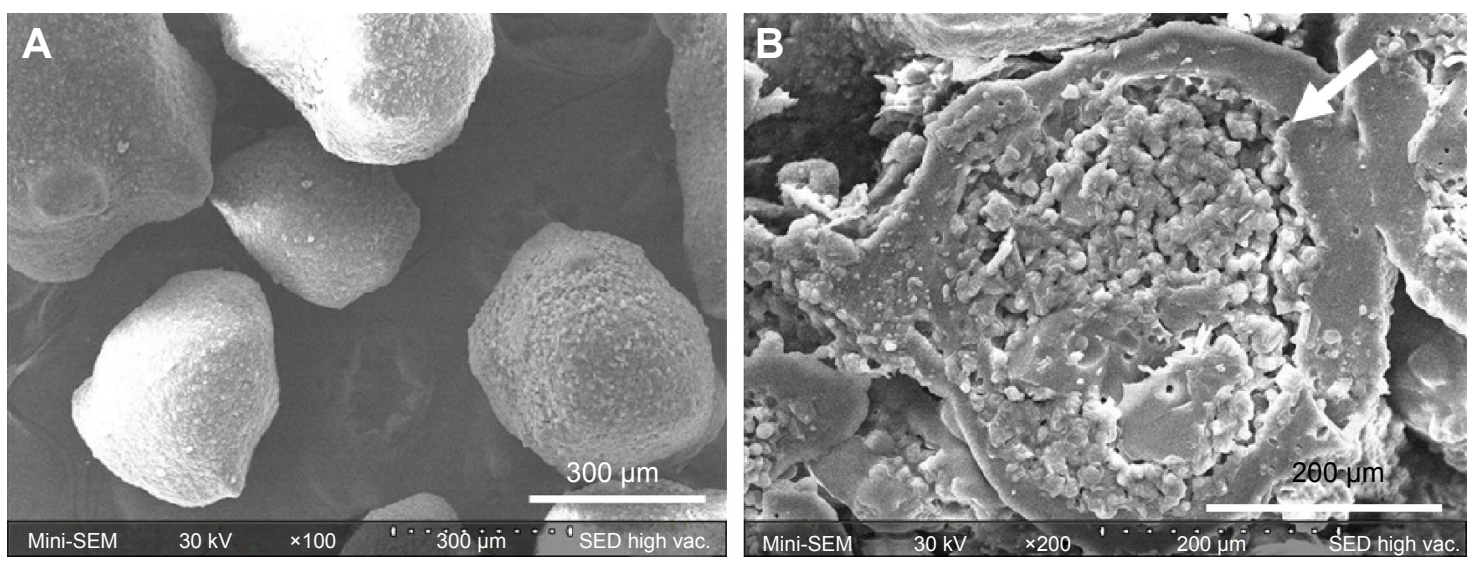

Figure 4 Scanning electron microphotographs of $(\mathbf{A})$ the surface of ECPs and $(\mathbf{B})$ cross-section of ECPs-T.

Note: Arrow indicates the ECP embedded in the tablet.

Abbreviations: ECP, enteric-coated pellet; ECPs-T, ECPs embedded tablet. 
technique were spherical. The particle size was homogeneous, ranging from 250 to $500 \mu \mathrm{m}$. The coated surface of ECPs was smooth and homogeneous, indicating that a continuous enteric coating layer was successfully formed onto the probiotic pellets.

The cross-sectional image of ECPs-T F8 suggested that HPMCAS-based coating layer on the pellets was intact without rupture and/or loss of integrity after the compression procedure (Figure 4B). The highly compressible excipients such as MCC, crospovidone, and calcium silicate displayed robust cushioning effect during the compression. These results are consistent with a previous report that pharmaceutical excipients composing of MCC, polyethylene glycol 3350 , and crospovidone were suitable for minimum damage to coated film. ${ }^{16}$

\section{Viability of probiotics in the preparation process}

The majority of manufacturing procedures involves contact of strains with aqueous and/or organic solvents during the mixing and/or coating process, exposure to high temperatures during the drying process, and under pressure during the compression, which can cause considerable loss of viability during the preparation process. ${ }^{11}$ To avoid and/or minimize bacterial stress during formulation, bacteria-loaded pellets were fabricated by dry coating technique without using any solvents. They were then directly compressed into tablets with compatible cushioning agents. The survival rates of living bacteria immediately after ECP preparation and after compaction of pellets into tablets are shown in Figure 5. The dry enteric coating process allowed the survival of living bacteria L. acidophilus and E. faecalis (Figure 5) by ensuring that these microorganisms had no contact with aqueous and/or organic solvents or high temperatures

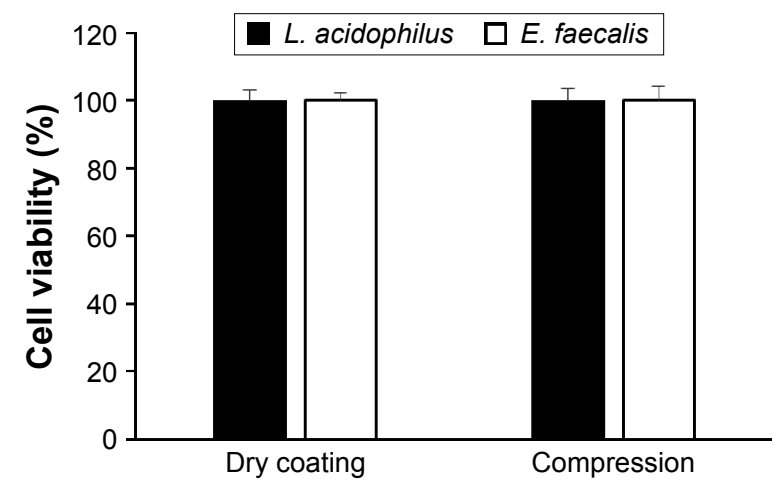

Figure 5 Survival rate of probiotic bacteria during the dry powder coating process and under compression of ECPs into tablet dosage form.

Note: Data are expressed as mean \pm SD values $(n=3)$.

Abbreviations: ECPs, enteric-coated pellets; E. faecalis, Enterococcus faecalis; L. acidophilus, Lactobacillus acidophilus; SD, standard deviation. during the encapsulation process. On the other hand, there was no significant difference in bacterial count before and after compression (Figure 5), indicating that these highly compressible excipients effectively lessened the additional stress to bacteria during the compression process.

\section{Storage stability of probiotics in ECPs-Ts}

Stability of probiotic bacteria in terms of cell viability is one major index that governs the efficiency of pharmaceutical excipients and dosage forms in order to protect living bacteria during a relatively long shelf life. ${ }^{27}$ Many studies have shown that the majority of microorganisms will lose their feasibility over time, even at room temperature. ${ }^{28}$ In the case of bare bacteria, storage at room temperature caused a significant decrease in the viability of L. acidophilus and E. faecalis (Figure 6A and B, respectively). After 1 month of storage, the survival rates of L. acidophilus and E. faecalis were only $47 \%$ and $61 \%$, respectively. Compression of uncoated living bacteria with other compounds had an even worse effect on the viability of living bacteria, showing $<0.1 \%$ and $53 \%$ of residual content after 1 month of storage. This result might be due to the antimicrobial properties of the aforementioned natural ingredients as reported for swertia herb powder and cinnamon bark powder. ${ }^{29,30}$ Andilac-S capsule (Il-Yang Pharm., Seoul, Korea), a commercially available product, could not assure the storage stability of $L$. acidophilus strain under ambient condition (Figure 6A), even though these involved the enteric materials.

On the other hand, the BIOR tablet (Unimed Pharmaceutical Inc., Seoul, Korea) provided improved storage stability of E. faecalis compared to the bare bacteria. The survival rates of both strains of bacteria were significantly improved through HPMCAS-based ECP preparations (Figure 6A and B). In particular, the survival rates of both microorganisms in ECPs-T were significantly higher than those of uncoated bacteria or ECPs. Using the ECPs-T formula, the survival rates of L. acidophilus and E. faecalis after 1 month were $99 \%$ and $101 \%$, respectively. The survival rates were maintained over $42 \%$ and $76 \%$ after 6 months of storage, while those of ECPs after 6 months were $30 \%$ and $63 \%$, respectively (Figure 6). These results indicate that encapsulation of both strains into the pellets can improve the storage stability, and the compression into tablets can further enhance the thermal tolerance of these microorganisms, by providing an additional physical barrier to isolate the living bacteria from external environment.

\section{Acid tolerability of probiotics in ECPs-T}

The survival rates of $L$. acidophilus and E. faecalis after exposure to acidic medium $(\mathrm{pH} 1.2)$ for 30 minutes are 
A

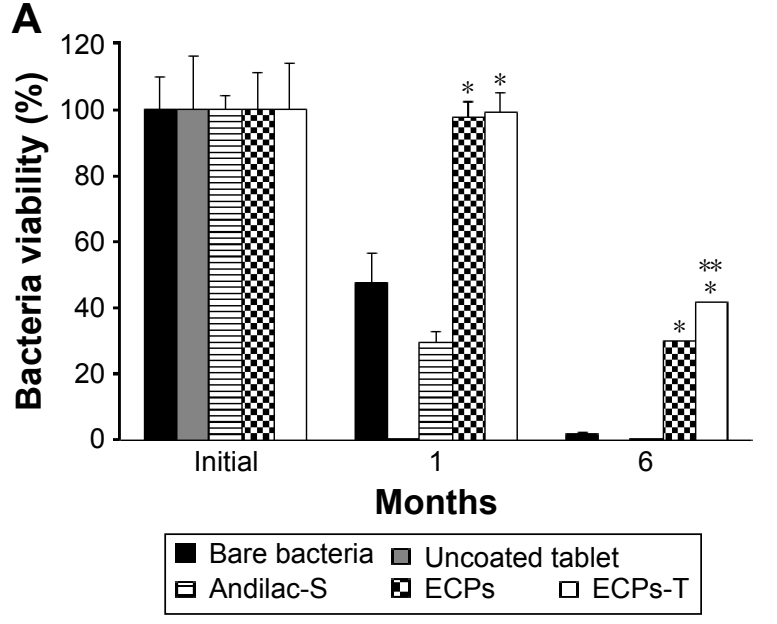

B

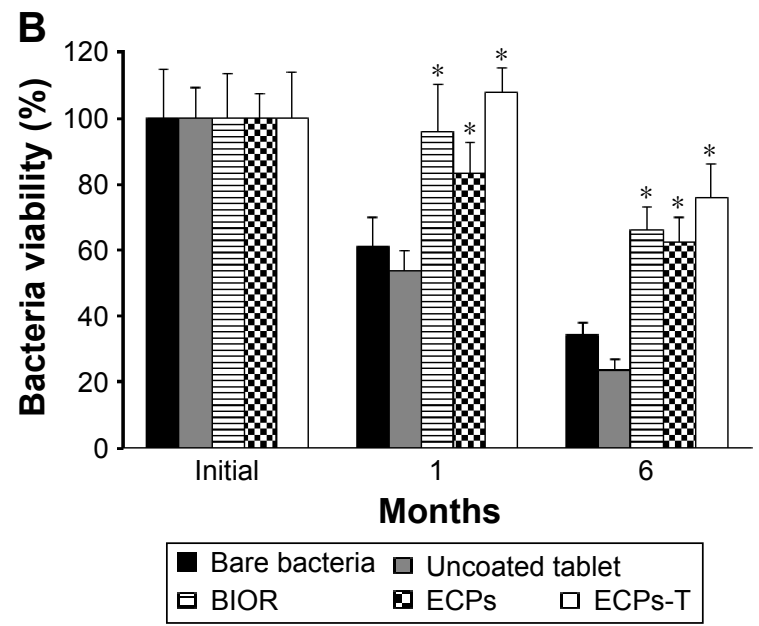

Figure 6 Storage stability of (A) L. acidophilus and (B) E. faecalis in ECPs-T in comparison to corresponding bare bacteria, uncoated probiotic tablet, marketed products, and ECPs under ambient storage conditions $\left(25^{\circ} \mathrm{C} / 60 \%\right.$ relative humidity) for 6 months.

Notes: To compare the bacterial storage viability, two marketed products, Andilac-S capsule (II-Yang Pharm. Co., Ltd., Gyeonggi-do, Korea) or BIOR tablet (Unimed Pharmaceutical Inc., Seoul, Korea) containing L. acidophilus or E. faecalis, respectively, were used. Data represent the mean \pm SD ( $n=3$ ), and statistical analysis was performed using Student's $t$-test; $* P<0.05$ versus bare bacteria; $* * P<0.05$ versus ECPs.

Abbreviations: ECPs, enteric-coated pellets; ECPs-T, enteric-coated pellets embedded tablet; E. faecalis, Enterococcus faecalis; L. acidophilus, Lactobacillus acidophilus; SD, standard deviation.

shown in Figure 7. The numbers of both the viable bacteria were rapidly decreased to $<0.1 \%$ in the case of free bacteria, uncoated probiotic tablet, and marketed products because these microorganisms had extremely low survival ability at $\mathrm{pH}<3.0 .^{7}$ On the other hand, the survival rates of these bacteria encapsulated in the ECPs were significantly higher than those of free bacteria, providing $>18 \%$ survival rate for both living bacteria. ECPs-T exhibited the greatest survival rate, showing significant differences from bare bacteria and ECPs. The survival rates of $L$. acidophilus and E. faecalis were approximately 54\% and 32\% higher, respectively, than those of ECPs by diminishing the penetration of aqueous medium into the dosage form more compactly. The result is coincided with a previous report that tablet form could preserve the bacterial integrity until it reaches to small and/or large intestine because of low water activity. ${ }^{31}$

\section{In vivo intestinal protective effect of ECPs-T}

The intestinal barrier is the first line of defense to protect the body against pathogens and food allergens entering the intestinal tract. Impairment of the intestinal barrier is highly associated with the pathogenesis of several diseases, including inflammatory bowel diseases, celiac disease, gastrointestinal infections, and diarrhea. ${ }^{3,32}$ Endotoxins are fragments of Gram-negative bacteria derived from the gut. It is well documented that endotoxins can impair gut barrier function and increase bacterial translocation. They can cross the
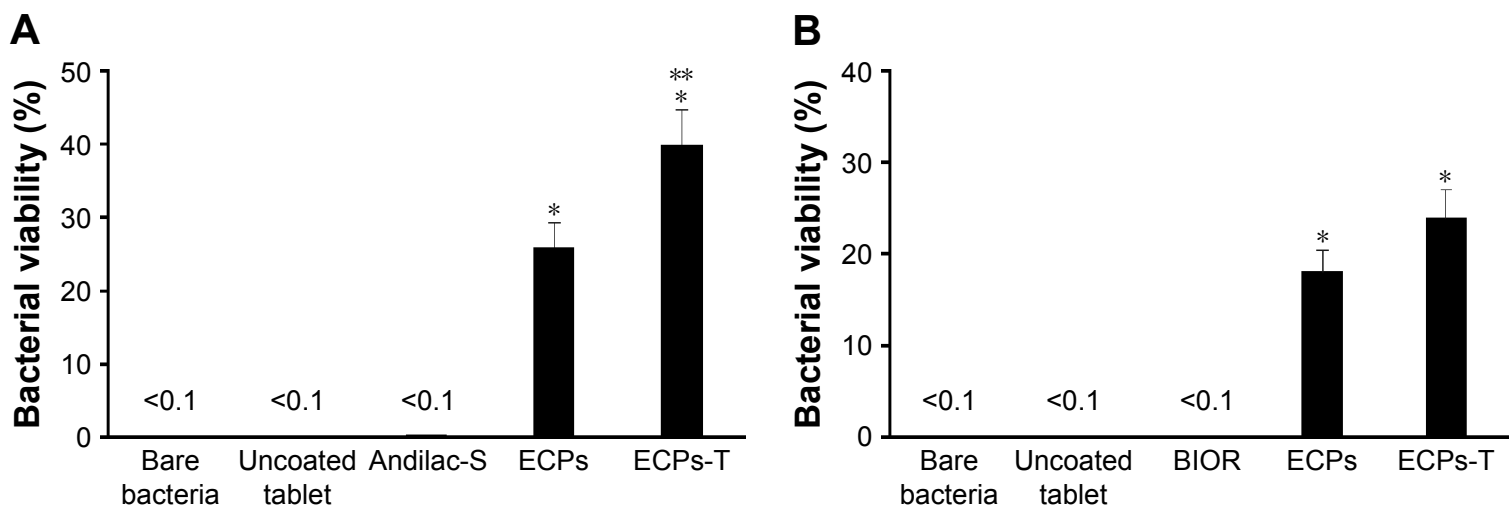

Figure 7 Bacterial viability of (A) L. acidophilus and (B) E. faecalis inside ECPs-T after immersion in acidic medium in comparison to that of free bacteria, uncoated probiotic tablet, marketed products, and ECPs.

Notes: Data represent the mean \pm SD $(n=3)$, and statistical analysis was performed using Student's $t$-test; $* P<0.05$ versus bare bacteria; $* * P<0.05$ versus ECPs.

Abbreviations: ECPs, enteric-coated pellets; ECPs-T, enteric-coated pellets embedded tablet; E. faecalis, Enterococcus faecalis; $L$. acidophilus, Lactobacillus acidophilus. 
intestinal mucosa and enter the blood circulatory system, thus stimulating innate immune response from the adipose tissue, liver, and skeletal muscle, leading to the production of proinflammatory cytokines. ${ }^{33-35}$ Urao et al reported that oral intake of probiotics by infants could improve the ratio of intestinal flora, thereby decreasing serum endotoxin produced by potentially pathogenic microorganisms. ${ }^{36}$ Chang et al also revealed that a probiotic preparation (VSL\#3, Danisco) could reduce serum ammonia and endotoxemia, thus reversing encephalopathy in $50 \%$ of patients. ${ }^{37}$ In this regard, the protective effect of ECPs-T was evaluated in rats by assessing its inhibitory effect on intestinal translocation of endotoxin compared to those of bare bacteria and marketed products (TGK-IR and VSL\#3) with proven ability to strengthen the intestinal barrier. ${ }^{37,38}$

As shown in Figure 8, no endotoxin was detected in the sham group, whereas the endotoxin level was significantly elevated in vehicle-treated group after endotoxin dosing $(818 \mathrm{EU} / \mathrm{mL})$. A considerable reduction in the amount of endotoxin in the plasma was observed in the groups administered with free probiotics, marketed products (TGK-IR and VSL\#3), or ECPs-T, indicating that probiotic bacteria could prevent endotoxin and other bacterial products from passing gut lumen into systemic circulation. Living bacteria might strengthen the physical barrier function of the intestinal membrane by facilitating mucin production, enhancing the level of tight junction proteins and hindering the disruption of tight junctions by pathogens. ${ }^{39-41}$ Chang et al reported that intake of probiotic bacteria for 2 days significantly lowered the expression of tumor necrosis factor alpha level, thus promoting the expression of tight junction proteins and decreasing epithelial translocation of endotoxin in rat model of alcoholic intestinal injury. ${ }^{37}$

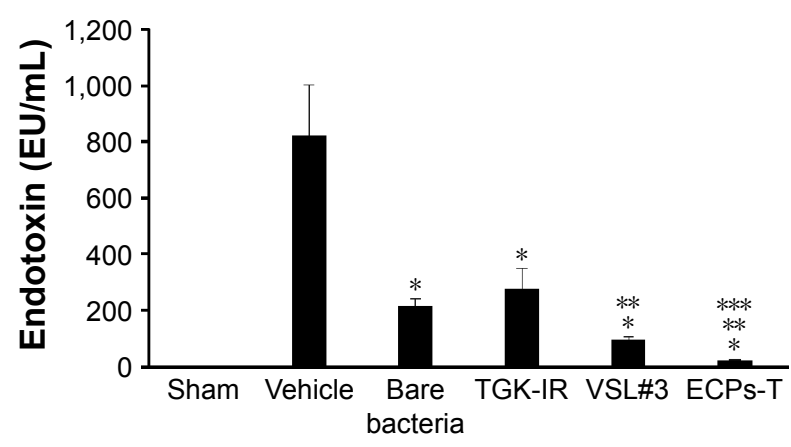

Figure 8 Effect of repeated administration of ECPs-T formulation on plasma endotoxin concentrations in normal rats.

Notes: Data represent the mean $\pm S D(n=5)$, and statistical analysis was performed using Student's $t$-test; $* P<0.05$ versus vehicle-treated group; $* * P<0.05$ versus bare bacteria; and $* * * P<0.05$ versus VSL\#3 (Danisco, Madison, WI, USA). Plasma endotoxin levels were measured by LAL assay.

Abbreviations: ECPs-T, enteric-coated pellets embedded tablet; LAL, Limulus amebocyte lysate.
In particular, the plasma level of endotoxin in the ECPsT-treated group (20 EU/mL) was remarkably lower than that of bare bacteria- or marketed products-treated groups. The amount of endotoxin in the plasma was only one-tenth $(P<0.05)$ or one-fifth $(P<0.05)$ of the free bacteria or VSL\#3 at the same dose. On the other hand, there was no significant difference in the plasma level of endotoxin between the bare bacteria-treated $(213 \mathrm{EU} / \mathrm{mL})$ and TGK-IR-treated (273 EU/mL) groups. These results suggest that ECPs-T can protect living bacteria from the adverse gastrointestinal environment more effectively to deliver and populate them into the gut, leading to enhanced intestinal barrier function. We have previously demonstrated that facilitated intestinal delivery of living bacteria led to a more reinforced mucosal barrier function against pathogenic material. ${ }^{11}$ Based on these findings, we concluded that a novel multiple-unit tablet could be beneficial for strengthening the intestinal barrier function.

\section{Conclusion}

A novel tablet dosage form of probiotic bacteria was fabricated in order to increase the viability of probiotic strains under storage conditions and to amplify its intestinal protective effect. The ECPs-T system employing MCC and calcium silicate as cushioning agent exhibited markedly higher storage stability and acid tolerability as well as appropriate physical properties. Moreover, regular intake of ECPs-T noticeably lessened the intestinal penetration of endotoxin to the intestinal lumen. Therefore, the novel ECPs-T may be a promising formula for improving bacterial viability and amplifying the intestinal protective effect in human gut.

\section{Disclosure}

The authors report no conflicts of interest in this work.

\section{References}

1. Kaur IP, Chopra K, Saini A. Probiotics: potential pharmaceutical applications. Eur J Pharm Sci. 2002;15:1-9.

2. Sanders ME. Considerations for use of probiotic bacteria to modulate human health. $J$ Nutr. 2000;130(2S Suppl):384S-390S.

3. Gratz SW, Mykkanen H, El-Nezami HS. Probiotics and gut health: a special focus on liver diseases. World J Gastroenterol. 2010;16:403-410.

4. Gismondo MR, Drago L, Lombardi A. Review of probiotics available to modify gastrointestinal flora. Int J Antimicrob Agents. 1999;12:287-292.

5. Dunne C. Adaptation of bacteria to the intestinal niche: probiotics and gut disorder. Inflamm Bowel Dis. 2001;7:136-145.

6. Vinderola CG, Bailo N, Reinheimer JA. Survival of probiotic microflora in Argentinian yoghurts during refrigerated storage. Food Res Int. 2000; 33:97-102.

7. Kailasapathy K, Chin J. Survival and therapeutic potential of probiotic organisms with reference to Lactobacillus acidophilus and Bifidobacterium spp. Immunol Cell Biol. 2000;78:80-88.

8. Berrada N, Lemeland JF, Laroche G, Thouvenot P, Piaia M. Bifidobacterium from fermented milks: survival during gastric transit. J Dairy Sci. 1991;74:409-413. 
9. Bouhnik Y, Pochart P, Marteau P, Arlet G, Goderel I, Rambaud JC. Faecal recovery in humans of viable Bifidobacterium sp. ingested in fermented milk. Gastroenterology. 1992;102:875-878.

10. Vidhyalakshmi R, Bhakyaraj R, Subhasree RS. Encapsulation "the future of probiotics" - a review. Adv Biol Res. 2009;3:96-103.

11. Park HJ, Lee GY, Jun JH, et al. Formulation and in vivo evaluation of probiotics-encapsulated pellets with hydroxypropyl methylcellulose acetate succinate (HPMCAS). Carbohydr Polym. 2016;136:692-699.

12. Stadler M, Viernstein $H$. Optimization of formulation containing viable lactic acid bacteria. Int J Pharm. 2003;256:117-122.

13. Zeeshan F, Peh KK, Tan YT. Exploring the potential of a highly compressible microcrystalline cellulose as novel tableting excipient in the compaction of extended-release coated pellets containing an extremely water-soluble model drug. AAPS PharmSciTech. 2009; 10:850-857.

14. Chan ES, Zhang Z. Encapsulation of probiotic bacteria Lactobacillus acidophilus by direct compression. Food Bioprod Process. 2002;80: 78-82.

15. Poulin JF, Caillard R, Subirade M. $\beta$-Lactoglobulin tablets as a suitable vehicle for protection and intestinal delivery of probiotic bacteria. Int J Pharm. 2011;405:47-54.

16. Torrado JJ, Augsburger LL. Effect of different excipients on the tableting of coated particles. Int J Pharm. 1994;106:149-155.

17. Vergote GJ, Kiekens F, Vervaet C, Remon JP. Wax beads as cushioning agents during the compression of coated diltiazem pellets. Eur J Pharm Sci. 2002;17:145-151.

18. Obara S, Maruyama N, Nishiyama Y, Kokubo H. Dry coating: an innovative enteric coating method using a cellulose derivative. Eur $J$ Pharm Biopharm. 1999;47:51-59.

19. Winding A, Binnerup SJ, Sørensen J. Viability of indigenous soil bacteria assayed by respiratory activity and growth. Appl Environ Microbiol. 1994;60:2869-2875.

20. Hwang RC, Peck GR. A systematic evaluation of the compression and tablet characteristics of various types of microcrystalline cellulose. Pharm Technol. 2001;24:112-132.

21. Patel S, Kaushal AM, Bansal AK. Compression physics in the formulation development of tablets. Crit Rev Ther Drug Carrier Syst. 2006;23: $1-65$.

22. Bolhuis GK, Armstrong NA. Excipients for direct compaction - an update. Pharm Dev Technol. 2006;11:111-124.

23. Al-Ibraheemia ZAM, Anuara MS, Taipa FS, Aminb MCI, Tahirc SM, Mahdia AB. Deformation and mechanical characteristics of compacted binary mixtures of plastic (microcrystalline Cellulose), elastic (sodium starch glycolate), and brittle (lactose monohydrate) pharmaceutical excipients. Particul Sci Technol. 2013;31:561-567.

24. Rubinstein MH. Tablets. In: Aulton ME, Aulton ME, editors. Pharmaceutics: The Science of Dosage form Design. London: Churchill Livingstone; 1988:304-321.

25. Asano T, Tsubuku S, Sugawara S, et al. Changes in volume and compression energy upon compression of calcium silicate tablets. Drug Dev Ind Pharm. 1997;23:679-685.
26. Vervaet C, Yliruusi J, De Smedt S, Mehuys M. Table Formulation of Porous Silicon Microparticles for Improved Dissolution of Poorly Soluble Drug Materials. Ghent: Ghent University; 2009.

27. Klayraung S, Viernstein H, Okonogi S. Development of tablets containing probiotics: effects of formulation and processing parameters on bacterial viability. Int J Pharm. 2009;370:54-60.

28. Ross RP, Desmond C, Fitzgerald GF, Stanton C. Overcoming the technological hurdles in the development of probiotic foods. $J$ Appl Microbiol. 2005;98:1410-1417.

29. Zaika LL. Spices and herbs: their antimicrobial activity and its determination. J Food Saf. 1998;9:97-118.

30. Roy P, Abdulsalam FI, Pandey DK, Bhattacharjee A, Eruvaram NR, Malik T. Evaluation of antioxidant, antibacterial, and antidiabetic potential of two traditional medicinal plants of India: Swertia cordata and Swertia chirayita. Pharmacognosy Res. 2015;7:S57-S62.

31. Muller C, Mazel V, Dausset C, et al. Study of the Lactobacillus rhamnosus $\mathrm{Lcr} 35^{\circledR}$ properties after compression and proposition of a model to predict tablet stability. Eur J Pharm Biopharm. 2014;88:787-794.

32. Ouwehand AC. Antiallergic effects of probiotics. J Nutr. 2007;137: 794-797.

33. Al-Attas OS, Al-Daghri NM, Al-Rubeaan K, et al. Changes in endotoxin levels in T2DM subjects on anti-diabetic therapies. Cardiovasc Diabetol. 2009;8:20.

34. Miller M, McTernan P, Harte A, et al. Ethnic and sex differences in circulating endotoxin levels: a novel marker of atherosclerotic and cardiovascular risk in a British multi-ethnic population. Atherosclerosis. 2009;203:494-502.

35. Harte AL, da Silva NF, Creely SJ, et al. Elevated endotoxin levels in non-alcoholic fatty liver disease. J Inflamm. 2010;30:7-15.

36. Urao M, Fujimoto T, Lane GJ, Seo G, Miyano T. Does probiotics administration decrease serum endotoxin levels in infants? J Pediatr Surg. 1999;34:273-276.

37. Chang B, Sang L, Wang Y, Tong J, Zhang D, Wang B. The protective effect of VSL\#3 on intestinal permeability in a rat model of alcoholic intestinal injury. BMC Gastroenterol. 2013;13:151.

38. Yonejima Y, Mori Y, Ushida K. Effect of a tablet containing probiotic bacteria and stomachic herbs on human fecal microbiota. Biosci Microflora. 2008;27:87-92.

39. Commane DM, Shortt CT, Silvi S, Cresci A, Hughes RM, Rowland IR. Effects of fermentation products of pro- and prebiotics on transepithelial electrical resistance in an in vitro model of the colon. Nutr Cancer. 2005;51:102-109.

40. Isolauri E, Salminen S. Probiotics, gut inflammation and barrier function. Gastroenterol Clin North Am. 2005;34:437-450.

41. Caballero-Franco C, Keller K, De Simone C, Chadee K. The VSL\#3 probiotic formula induces mucin gene expression and secretion in colonic epithelial cells. Am J Physiol Gastrointest Liver Physiol. 2007; 292:315-322.
Drug Design, Development and Therapy

\section{Publish your work in this journal}

Drug Design, Development and Therapy is an international, peerreviewed open-access journal that spans the spectrum of drug design and development through to clinical applications. Clinical outcomes, patient safety, and programs for the development and effective, safe, and sustained use of medicines are a feature of the journal, which

\section{Dovepress}

has also been accepted for indexing on PubMed Central. The manuscript management system is completely online and includes a very quick and fair peer-review system, which is all easy to use. Visit http://www.dovepress.com/testimonials.php to read real quotes from published authors. 